\title{
Tingkat Pelayanan (Los) Trotoar \\ Pada Ruas Jalan Utama Kota Surabaya \\ (Kasus Jalan Wonokromo, Jalan Raya Darmo, Jalan Basuki Rahmat, Jalan Urip Sumohardjo, Jalan Embong Malang, dan Jalan Tunjungan)
}

\author{
Djoko Sulistiono, Amalia Firdaus M, Sulchan Arifin \\ Program Studi Diploma Teknik Sipil FTSP ITS \\ Email :djokosulis2016@yahoo.com
}

\begin{abstract}
The big cities's rapid economic growth in Indonesia, including Surabaya, followed by an increase of people / goods movement. This movement particularly pedestrian movement should be facilitated by the Government with the provision of adequate sidewalks. It happens, in area trade and office area in Surabaya, such as sidewalks Jalan Wonokromo, Jalan Raya Darmo, Jalan Basuki Rahmat, Jalan Urip Sumohardjo, Jalan Embong Malang, and Jalan Tunjungan. Issues, how the level of service (LOS) above the sidewalk and how the relationship between speed and density of pedestrian flows, which would be answered through discussion.

Discussion about the level of service refers to Regulation of the Minister of Public Work No. 03 / PRT / M / 2014. Then, with the data primary survey about pedestrian volume, local conditions and also secondary data from authorized institutions such as the function of the road, so we can determine the level of service the sidewalk.

Results, The Regulation of the Minister (2014) obtained a level of service on all road pavement is $A$. In addition, the obtained relationship between speed, density and volume of pedestrians. The relationship among the most powerful is the relationship between velocity and density on the sidewalk Jalan Urip Sumohardjo west side, with the equation $Y=-2176 X+67.53$ in $R 2=0.62$ and $r=0.78$. The relationship between the volume of pedestrians and density is very strong on all pavement roads with $R 2>0.95$. One of the strongest is the sidewalk Jalan Basuki Rahmat west side of the equation $Y=-677.14+0,0004 X 2+57,349 X$ at $R 2=0.99$ and $r=0.998$.
\end{abstract}

Keywords: sidewalk, service level and pedestrians

\section{Abstrak}

Pertumbuhan ekonomi yang pesat di kota besar Indonesia, termasuk Surabaya diikuti peningkatan pergerakan orang/barang. Pergerakan ini khususnya pergerakan pejalan kaki harus di fasilitasi oleh Pemerintah dengan penyediaan trotoar yang memadai. Demikian pula yang terjadi di daerah perdagangan, perkantoran di kota Surabaya, seperti trotoar ruas Jalan Wonokromo, Jalan Raya Darmo, Jalan Basuki Rahmat, Jalan Urip Sumohardjo, Jalan Embong Malang, dan Jalan Tunjungan. Permasalahan, bagaimana tingkat pelayanan (LOS) trotoar tersebut diatas dan bagaimana hubungan kecepatan dan kepadatan arus pejalan kaki, yang hasilnya bisa terjawab melalui pembahasan.

Pembahasan mengenai tingkat pelayanan mengacu pada Peraturan Menteri Perkerjaan Umum No 03/PRT/M/2014. Kemudian dengan data yang diperoleh dari survey primer volume pejalan kaki, kondisi setempat dan data sekunder dari instansi yang berwenang seperti fungsi jalan maka dapat ditentukan tingkat pelayanan trotoar.

Hasil pembahasan sesuai Peraturan Menteri (2014) diperoleh tingkat pelayanan trotoar pada semua ruas jalan adalah A. Selain itu, diperoleh hubungan antara kecepatan, kepadatan dan volume pejalan kaki. Hubungan tersebut diantaranya yang paling kuat adalah hubungan antara kecepatan dan kepadatan pada trotoar Jalan Urip Sumohardjo sisi barat, dengan persamaan Y $=-2176 \mathrm{X}+67,53$ pada $R^{2}=0,62$ dan $r=0,78$. Hubungan antara volume pejalan kaki dan kepadatan sangat kuat pada semua trotoar ruas jalan dengan $R^{2}>0,95$. Salah satu yang terkuat adalah trotoar ruas Jalan Basuki Rahmat sisi barat dengan persamaan $Y=-677,14 X^{2}+57,349 X$ $+0,0004$ pada $R^{2}=0,99$ dan $r=0,998$.

Kata kunci : trotoar, tingkat pelayanan dan pejalan kaki 


\section{Pendahuluan}

Seiring dengan pertumbuhan ekonomi yang pesat di kota besar Indonesia, termasuk Surabaya mengakibatkan pergerakan orang, barang semakin tinggi. Pergerakan ini, khususnya pergerakan orang (pejalan kaki) banyak terjadi di pusat perbelanjaan, perkantoran, sekolah, dan lain-lain. Pergerakan yang terjadi harus diberikan fasilitas oleh pemerintah berupa trotoar yang memadai untuk keselamatannya dan kelancaran lalu lintas di sekitarnya. Demikian pula yang terjadi pada trotoar ruas jalan utama Kota Surabaya, seperti Jalan Wonokromo, Jalan Raya Darmo, Jalan Basuki Rahmat, Jalan Urip Sumohardjo, Jalan Embong Malang, dan Jalan Tunjungan.

Semua fasilitas trotoar ini harus di evaluasi tingkat pelayanannya ( $L O S$ ) dalam melayani masyarakat, khususnya bagi para pejalan kaki. Hal ini karena hampir semua aktivitas transportasi tersebut selalu di awali dan di akhiri dengan jalan kaki. Pembangunan trotoar yang di biayai masyarakat melalui APBD Tingkat II, harus dapat memberikan manfaat bagi penggunaannya, yaitu masyarakat Surabaya.

Pengertian trotoar menurut RSNI T-142004 Geometri Jalan Perkotaan adalah jalur pejalan kaki, selain jembatan penyebrangan dan trowongan kemudian pengertian trotoar menurut Peraturan Menteri No. 03/PRT/M/2014 Tentang Pedoman Perencanaan, Penyediaan dan pemanfaatan prasarana dan sarana pejalan kaki di kawasan perkotaan adalah jalur pejalan kaki yang sejajar sumbu jalan, lebih tinggi dari permukaan jalan untuk keselamatan pejalan kaki. Trotoar harus ditempatkan di sisi luar bahu jalan dan jika jalan di lengkapi tempat parkir, maka trotoar di tempatkan di sebelah luar area parkir. Kemudian bila ruas jalan tersedia jalur hijau yang terletak di sebelah luar bahu jalan atau area parkir, maka trotoar di tempatkan di sebelah luar jalur hijau.

Permasalahan, bagaimana tingkat pelayanan $(L O S)$ trotoar Jalan tersebut. Kemudian bagaimana hubungan antara kecepatan dan kepadatan pejalan kaki. Kepadatan dan volume pejalan kaki dan lain - lain di trotoar. Semua diharapkan terjawab dalam pembahasan ini, sehingga maksud dan tujuan penulisan yaitu mengetahui tingkat pelayanan trotoar di beberapa ruas jalan utama dan hubungan kecepatan, kepadatan, dan volume pejalan kaki, dapat tercapai.

\section{Metodologi}

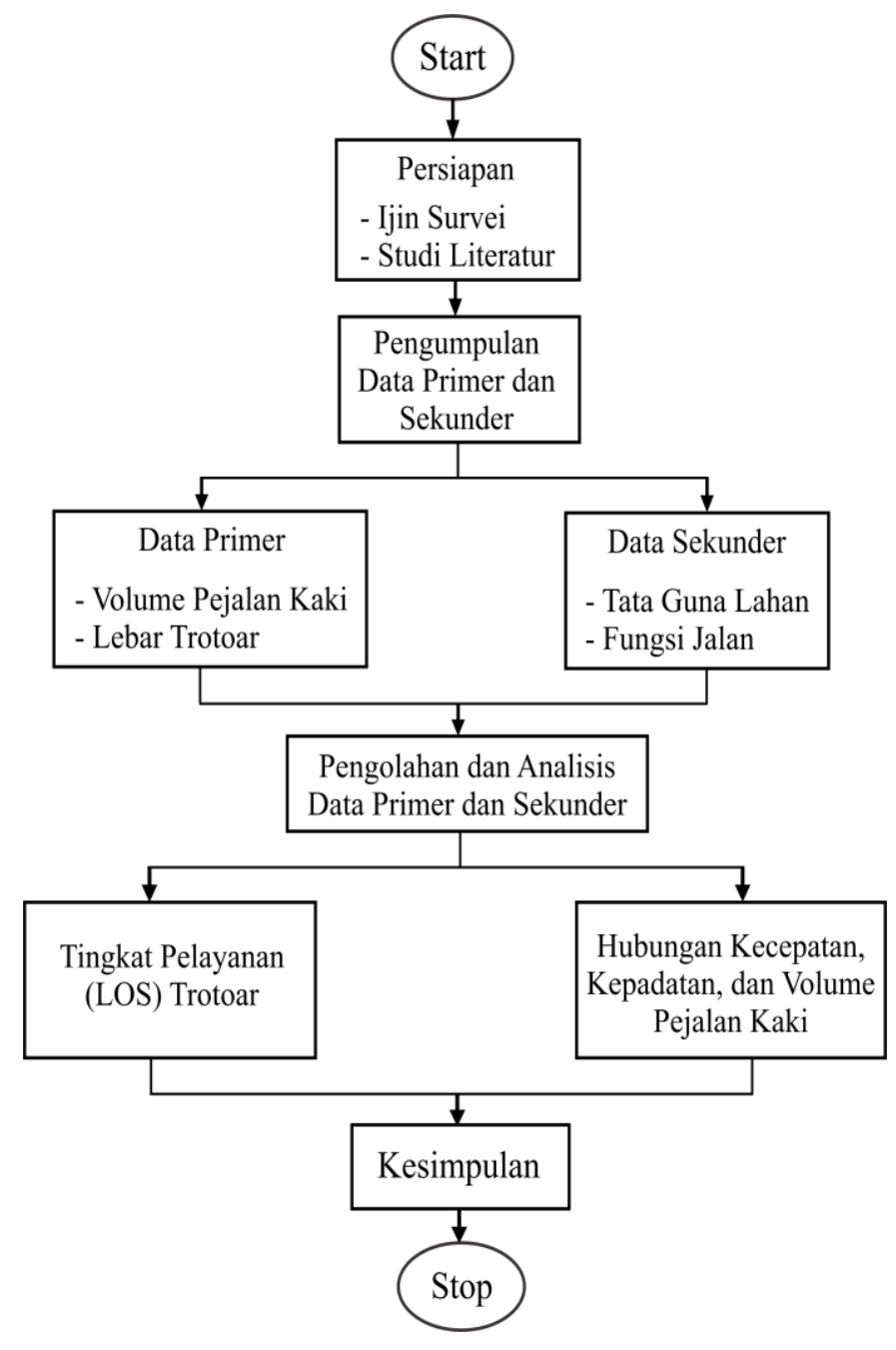




\section{Pembahasan}

Lebar trotoar minimum sesuai spesifikasi trotoar (SNI 03-2447-1991) tergantung pada fungsi jalan, yaitu untuk jalan arteri primer/sekunder, kolektor primer/sekunder, dan lokal sekunder sebesar 1,5 meter. Tetapi lebar trotoar minimum sesuai Peraturan Menteri PU No 03/PRT/M/2014, tergantung tata guna lahan sekitarnya. Pusat pertokoan/perbelanjaan, daerah industri, perkantoran, sekolah, mempunyai lebar minimum 2 meter. Sedangkan daerah perumahan mempunyai lebar minimum 1,6 meter.

Lebar trotoar (W) dalam meter yang diperlukan tergantung kepada volume pejalan kaki $(\mathrm{P})$ dalam orang/meter/menit dan lebar tambahan $(\mathrm{N})$ dalam meter sesuai keadaan setempat dengan rumus sebagai berikut : $\boldsymbol{W}=\frac{P}{35}+N$
Sebagai contoh lebar tambahan (N) untuk jalan di daerah pasar adalah 1,5 meter, jalan di daerah perbelanjaan (bukan pasar) adalah 1 meter, dan jalan di daerah lain adalah 0,5 meter. Tetapi trotoar ini perlu ditambah lagi bila ada tiang lalu lintas/lampu, tanaman, keranjang sampah, pot bunga, dll, sampai maximum $1,50 \mathrm{~m}$.

Karakteristik pejalan kaki yang penting terkait dengan tingkat pelayanan trotoar atau Level of Service (LOS) adalah kecepatan berjalan (walking speed), arus pejalan kaki (walking density). Tingkat pelayanan (LOS) trotoar ditentukan oleh kebebasan pejalan kaki untuk memilih kecepatan berjalan yang diinginkan untuk mendahului pejalan kaki lain yang berjalan lebih lambat. Hubungan tingkat pelayanan dengan kecepatan (meter/menit) dan Jalur pejalan kaki ( $\mathrm{m}^{2} /$ orang) dan lain-lain diperlihatkan pada Tabel 1 .

Tabel 1. Hubungan Tingkat Pelayanan dengan Ruang, Laju Arus, Kecepatan, dan Rasio

\begin{tabular}{ccccc}
\hline $\begin{array}{c}\text { Tingkat Pelayanan } \\
(\text { LOS })\end{array}$ & $\begin{array}{c}\text { Jalur Pejalan } \\
\left(\mathrm{m}^{2} / \mathrm{org}\right)\end{array}$ & $\begin{array}{c}\text { Volume Pejalan } \\
\text { Kaki } \\
(\text { org/m/mnt })\end{array}$ & $\begin{array}{c}\text { Kecepatan } \\
(\mathrm{m} / \mathrm{mnt})\end{array}$ & $\begin{array}{c}\text { Ratio } \\
(\mathrm{V} / \mathrm{C})\end{array}$ \\
\hline A & $>12$ & $<6,7$ & $>4,5$ & $\leq 0,08$ \\
$\mathrm{~B}$ & $>3,6$ & $<23$ & $>4,17-4,25$ & $\leq 0,28$ \\
$\mathrm{C}$ & $>2,2$ & $<33$ & $>4,0-4,17$ & $\leq 0,4$ \\
$\mathrm{D}$ & $>1,4$ & $<50$ & $>3,75-4,0$ & $\leq 0,6$ \\
$\mathrm{E}$ & $>0,5$ & $<83$ & $>2,5-3,75$ & $\leq<1,0$ \\
$\mathrm{~F}$ & $<0,5$ & Beragam & $<45$ & 1,0
\end{tabular}

Sumber: Peraturan Menteri PU (2014)

Hasil perhitungan laju arus pejalan kaki (org/m/mnt) terkait tingkat pelayanan (LOS) yang diolah dari data survey di Jalan
Wonokromo, Jalan Basuki Rachmad dan Jalan Raya Darmo, ditunjukkan pada Tabel 2. 
Tabel 2. Perhitungan Laju Arus Pejalan Kaki dan Tingkat Pelayanan (LOS) trotoar Jalan Wonokromo, Jalan Basuki Rachmad dan jalan Raya Darmo.

\begin{tabular}{lll}
\hline Trotoar Ruas Jalan & Laju Arus (org/m/mnt) & Tingkat Pelayanan (LOS) \\
\hline Jl. Wonokromo & & \\
Sisi Barat & 0,76 & A \\
Sisi Timur & 0,45 & A \\
Jl. Basuki Rahmad & & \\
Sisi Barat & 0,21 & A \\
Sisi Timur & 0,21 & A \\
Jl. Raya Darmo & & \\
Sisi Barat & 0,31 & A \\
Sisi Timur & 0,67 & A \\
\hline
\end{tabular}

Sumber : Cahyono, H (2014)

Sesuai Tabel 2 diatas terlihat bahwa Tingkat Pelayanan (LOS) trotoar ruas Jalan Wonokromo, Jalan Basuki Rachmad dan Jalan Raya Darmo adalah A.

Kemudian hasil perhitungan Jalur Pejalan

Kaki $\left(\mathrm{m}^{2} /\right.$ orang) terkait tingkat pelayanan
(LOS) sesuai data survey di Jalan Urip Sumohardjo, Jalan Embong Malang dan Jalan Tunjungan Surabaya, ditunjukan pada Tabel 3.

Tabel 3. Hasil perhitungan Jalur Pejalan Kaki dan Tingkat Pelayanan (LOS) trotoar Jalan Urip Sumohardjo, Jalan Embong Malang dan Jalan Tunjungan.

\begin{tabular}{lll}
\hline Trotoar Ruas Jalan & $\begin{array}{l}\text { Jalur Pejalan Kaki } \\
\left(\mathrm{m}^{2} / \mathrm{org}\right)\end{array}$ & Tingkat Pelayanan (LOS) \\
\hline Jl. Urip Sumohardjo & & \\
Sisi Barat & 95,56 & A \\
Sisi Timur & 187,82 & A \\
Jl. Embong Malang & & \\
Sisi Barat & 82,52 & A \\
Sisi Timur & 32,81 & A \\
Jl. Tunjungan Surabaya & & \\
Sisi Barat & 115,13 & A \\
$\quad$ Sisi Timur & 68,37 & A \\
\hline
\end{tabular}

Sumber : Yuliandri, H (2014)

Sesuai Tabel 3 diatas terlihat bahwa Tingkat Pelayanan (LOS) trotoar ruas Jalan Urip Sumohardjo, Jalan Embong Malang adalah A. Tingkat pelayanan A seperti terlihat pada Tabel 2 dan Tabel 3 tersebut, menunjukkan bahwa Pemerintah Kota Surabaya telah memberi pelayanan yang baik bagi para pejalan kaki yang menggunakannya, tingkat pelayanan A ini dapat memberikan area yang cukup untuk memilih kecepatan berjalan kaki dan jarang terjadi konflik antar pejalan kaki.

Kemudian kebutuhan lebar trotoar (W) sesuai rumus yang ada, telah dihitung untuk dibandingkan dengan lebar efektif (We) 
yang ada pada saat ini, untuk mengetahui kecukupan lebar trotoar pada ruas jalan yang ditinjau.

Hasil perhitungan menunjukkan bahwa kebutuhan lebar trotoar telah mencukupi, kecuali trotoar pada ruas Jalan Embong Malang sisi timur. Lebar kebutuhan trotoar (W) tersebut sebenarnya masih perlu ditambah lagi, bila ada tiang lampu, pot bunga, keranjang sampah dan lain-lain sampai maximum 1,5 meter. Penilaian akan lebih baik bila ada survei ke pengguna trotoar dalam bentuk semantik deferensial dengan memakai satu atau lebih descriptor untuk setiap aspek atau kegiatan, sehingga dapat diketahui pelayanan trotoar ke penggunanya. Secara keseluruhan hasil perhitungan kebutuhan lebar trotoar (W) ditunjukkan pada Tabel 4 dan Tabel 5.

Tabel 4. Kebutuhan Lebar Trotoar (m) terkait dengan lebar efektif yang tersedia (m), pada ruas Jalan Wonokromo, Jalan Basuki Rahmad, dan Jalan Raya Darmo.

\begin{tabular}{llll}
\hline Trotoar Ruas Jalan $(\mathrm{m})$ & $\begin{array}{l}\text { Kebutuhan } \\
\text { Trotoar ( meter) }\end{array}$ & $\begin{array}{l}\text { Lebar } \\
\text { yang tersedia (m) }\end{array}$ & $\begin{array}{l}\text { Lebar trotoar Efektif } \\
\text { Jalan Wonokromo }\end{array}$ \\
$\begin{array}{llll}\text { - Sisi Barat } \\
\text { - Sisi Timur }\end{array}$ & 1,52 & 2,8 & Mencukupi \\
Jalan Raya Darmo & 1,51 & 2,8 & Mencukupi \\
- Sisi Barat & 1,50 & 3,0 & Mencukupi \\
- Sisi Timur & 1,52 & 3,0 & Mencukupi \\
Jalan Basuki Rahmat & & & Mencukupi \\
- Sisi Barat & 1,50 & 4,8 & Mencukupi \\
- Sisi Timur & 1,50 & 3,9 & \\
\hline
\end{tabular}

Sumber : Cahyono, H (2014)

Tabel 5. Kebutuhan lebar trotoar $(\mathrm{m})$ terkait lebar efektif yang tersedia (m), pada ruas Jalan Urip Sumohardjo, Jalan Embong Malang dan Jalan Tunjungan.

\begin{tabular}{lllll}
\hline Trotoar Ruas Jalan $(\mathrm{m})$ & $\begin{array}{l}\text { Kebutuhan } \\
\text { Trotoar }(\mathrm{W}) \text { dalam } \\
\text { meter }\end{array}$ & $\begin{array}{l}\text { Lebar } \\
(\mathrm{We}) \text { yang tersedia }(\mathrm{m})\end{array}$ & Keterangan \\
\hline $\begin{array}{l}\text { Jalan Urip Sumohardjo } \\
\quad \text { Sisi Barat }\end{array}$ & 1,51 & 4,6 & Mencukupi \\
$\quad$ - Sisi Timur & 1,50 & 4,6 & Mencukupi \\
Jalan Embong Malang & & & Mencukupi \\
$\quad$ - Sisi Barat & 1,52 & 5,8 & Mencukupi \\
- Sisi Timur & 1,54 & 1,2 & Mencukupi \\
Jalan Tunjungan & & & Mencukupi \\
$\quad$ - Sisi Barat & 1,51 & 3,5 &
\end{tabular}




\section{Kesimpulan}

Sesuai dengan hasil pembahasan, maka dapat disimpulkan hal-hal sebagai berikut:

1. Tingkat pelayanan (LOS) ruas jalan utama Surabaya, yaitu ruas Jalan Raya Wonokromo, Jalan Raya Darmo, Jalan Basuki Rahmat, Jalan Urip Sumohardjo, Jalan Embong Malang, dan Jalan Tunjungan semuanya adalah A, hal ini menunjukkan bahwa Pemerintah Kota Surabaya telah memberi pelayanan yang baik bagi warganya, yang menggunakan fasilitas trotoar.

2. Lebar kebutuhan trotoar (W) pada trotoar ruas jalan yang ditinjau telah mencukupi, kecuali trotoar ruas Jalan Embong Malang sisi timur.

3. Terdapat hubungan kecepatan dan kepadatan pejalan kaki untuk masing-masing ruas jalan Hubungan tersebut diantaranya yang paling kuat adalah hubungan antara kecepatan dan kepadatan pada trotoar Jalan Urip Sumohardjo sisi barat, dengan persamaan $\mathrm{Y}=$ $2176 X+67,53$ pada $R^{2}=0,62$ dan $r$ $=0,78$. Kemudian hubungan antara volume pejalan kaki dan kepadatan sangat kuat pada semua trotoar ruas jalan dengan $R^{2}>0,95$. Salah satu yang terkuat adalah trotoar ruas Jalan Basuki Rahmat sisi barat dengan persamaan yaitu $\mathrm{Y}=-677,14$ $X^{2}+57,349 X+0,0004$ pada $R^{2}=$ 0,99 dan $r=0,998$.

\section{DAFTAR PUSTAKA}

Khisty, C Jotin dan B.Kent Lall 2006.

"Dasar - dasar rekayasa tranportasi” Penerbit Erlangga Jakarta
Peraturan Menteri Perkerjaan Umum No 03/PRT/M/2014 tentang pedoman, penyediaan dan Pemanfaatan prasarana dan sarana pejalan kaki di kawasan perkotaan.

Sulistiono, Djoko, dan Hendri Cahyono, 2014. "Studi Evaluasi Tingkat Pelayanan Trotoar pada ruas jalan utama Kota Surabaya (Kasus Jalan Wonokromo, Jalan Raya Darmo dan Jalan Basuki Rahmat)” ,Skripsi Jurusan Teknik Sipil FTSP ITATS.

Sulistiono, Djoko, dan Halid Yuliandri, 2014. "Studi Evalusi Tingkat Pelayanan Trotoar pada Jalan Urip Sumohardjo, Jalan Embong Malang dan Jalan Tunjungan Surabaya", Skripsi Jurusan Teknik Sipil FTSP ITATS. 